\title{
Brief Review on the Causes, Diagnosis and Therapeutic Treatment of Gastritis Disease
}

Mohamed M Elseweidy ${ }^{*}$

Faculty of Pharmacy, Zagazig University, Zagazig, Egypt

*Corresponding author: Mohamed M Elseweidy, Faculty of Pharmacy, Zagazig University, Zagazig, Egypt, Tel: +20226074034; E-mail: mmElseweidy@yahoo.com

Received date: January 31, 2017; Accepted date: February 17, 2017; Published date: February 20, 2017

Copyright: (c) 2017 Elseweidy MM. This is an open-access article distributed under the terms of the Creative Commons Attribution License, which permits unrestricted use, distribution, and reproduction in any medium, provided the original author and source are credited.

\begin{abstract}
Gastritis represent a state of inflammation, irritation, or erosion of the stomach lining which may occur suddenly (acute) or gradually (chronic). Generally there is no universally accepted classification of gastritis and early classification was based mainly on the morphology, but recently pathogenic mechanisms have also been incorporated. The gastric mucosa is continuously exposed to many noxious factors, and Gastric protection aimed mainly to reduce or prevent the chemically induced acute hemorrhagic erosions which is exerted by compounds such as prostaglandins (PG) and SH derivatives without inhibiting acid secretion.

Common causes of gastritis are excessive alcohol consumption or prolonged use of non-steroidal antiinflammatory drugs (NSAIDs) such as aspirin or ibuprofen. It may also develop after major surgery, traumatic injury, burns, or severe infections. Chronic causes are infection with bacteria, primarily Helicobacter pylori (HP), chronic bile reflux, stress additionally certain autoimmune disorders can cause gastritis as well. The most common symptom is abdominal upset or pain, indigestion, abdominal bloating, nausea, vomiting and pernicious anemia. The current study here is focusing on the causes, clinical profile, inflammatory, immune response and autoimmune atrophic gastritis in affected individuals. Additional focuses are on different diagnostic tools for Helicobacter pylori infection (HP) and current therapeutic treatment.
\end{abstract}

Keywords: Gastritis; Clinical profile; Inflammatory and immune response; Autoimmune atrophic gastritis; Helicobacter pylori; Diagnosis and current medications

\section{Introduction}

\section{Overview and pathogenesis}

The term "gastritis" refer usually to inflammation, erosive state to the stomach lining tissue which may occur either instantly (acute) or gradually as chronic state [1]. Early classification of the disease was based on tissue morphology which has been changed now with the incorporation of the pathological mechanism. Classification of gastritis was introduced by the Sydney system in 1990, updated in 1995 and included both endoscopic and histological categories [2]. Exposure of the gastric mucosa to noxious factors are continually occur and its resistance to auto digestion by gastric secretion is remarkable and mainly attributed to the presence of mucus gel layer lining the inner surface and acting as tissue protective [3]. Many compounds like prostaglandins (PG) and SH derivatives can induce acute hemorrhagic erosions which can be prevented by the gastro protective mechanism as exerted by the lining mucous. The latter is referred to as complex aqueous mixture of mucin, Electrolytes, Enzymes, bacterial products and scared cells [4]. Its physiological mechanisms are multiple; include formation of thick mucus gel which protects the epithelial surface against noxious factors, irritation or through coating the ingested food for subsequent digestion.

\section{Causes of gastritis}

Common causes of gastritis are many like continued intake of alcoholic beverages or long intake of non-steroidal anti-inflammatory drugs (NSAIDS), Aspirin for Rheumatoids and Osteoarthritis patients [5] while Stress, chronic bile reflux, autoimmune disorders and HP infection are causal for chronic gastritis. The symptoms observed her are many like nausea, vomiting, indigestion, burning sensation and abdominal bloating [6]. Blood, stool tests and gastro endoscopy are mostly requested for Diagnosis.

\section{Morphological Patterns}

\section{Acute type}

Acute gastritis is mostly induced by many agents like certain drugs, bile, Ischemia, viral, fungal, radiation acute stress (shock) and direct trauma. Alcohol consumption does not cause chronic gastritis, but it erode however the mucosal lining of the stomach. Although low doses of alcohol, not the higher one which stimulate hydrochloric acid secretion. Long intake of NSAID may induce an acute erosive gastritis, mostly due to injury and reduced prostaglandin synthesis. Duodenumgastric bile reflux, long NSAID intake are causal factors for reactive or chemical gastritis (tortosity). Symptoms of the latter are many like cellular irritation of gastric surface associated with vasodilatation, congestion of gastric lamina propria, inflammatory cells and edema [7]. 


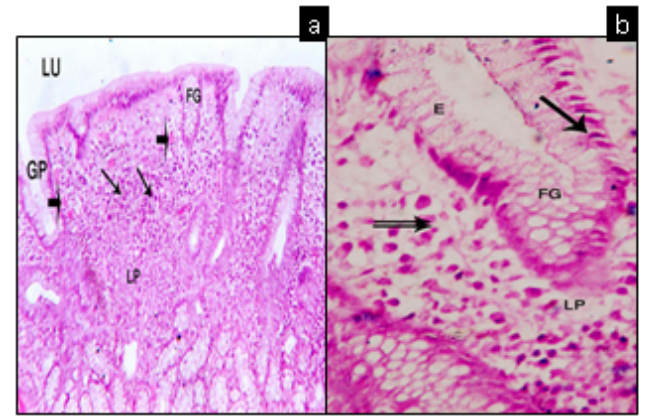

Figure 1: Histological section of human fundic gland of patient suffering from gastritis with anti $H$. pylori IgM positive group showing (a) X100 irregular short fundic gland (FG), wide gastric pit (GP), multiple inflammatory cells (arrows) and blood vessels (double arrows) filling lamina propria (LP), (b) X400 showing irregular simple columnar epithelium (E), small pyknotic nuclei (arrows) of cells lyningfundic gland (FG) and multiple inflammatory cells (double arrows) filling lamina propria (LP)[10].

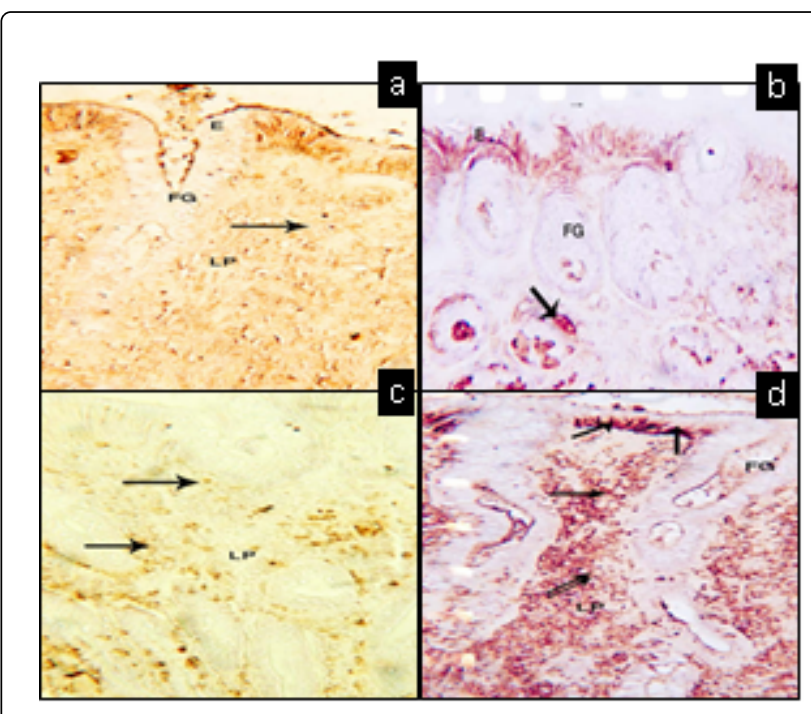

Figure 2: Immunostaining section of Gastritis patients $\operatorname{IgM}(+)$ category for (a) nitrotyrosine showing strong positive reaction in the epithelial (E) lining fundic gland (FG) and inflammatory cells (arrows) filling lamina propria (LP), (b) myeloperoxidase showingstrong positive reaction in the surface columnar epithelial cells (E) and other cells (arrows) lining fundic gland (FG) (c) iNOS showing strong positive reaction in the inflammatory cells (arrows) filling lamina propria (LP), (d) DNA fragmentation factor (DFF) showing strong positive reaction in the epithelial (arrows) lining fundic gland (FG) and inflammatory cells (double arrows) fill lamina propria (LP) (X200)[10].

\section{Chronic type}

Infiltration of inflammatory cells like plasma cells, lymphocytes represents an inflammatory changes (chronic type) in gastric mucosa, mainly attributed to HP infection along a disturbances in the secretion of pepsinogen enzyme, HCL additionally gastrin and somatostatin hormones. Increased apoptosis, hyper proliferation of the gastric epithelium are also observed during HP infection and is subsequently reduced upon treatment of the infection or eradication of HP [8]. Disturbances between the aggressive and cyto protective factors which maintain the integrity of the gastric mucosa represent a common mechanism of the injury. Inflammatory pattern her include massive increase of oxidative stress (high ROS), pepsinogen, gastrin and nitric acid synthesis (iNOS) with subsequent atrophy and G cells damage. Final apoptosis formation in different cell varieties may be attributed to peroxynitrite formed due to an interaction between $\mathrm{NO}$ and reactive oxygen species (ROS) (Figure 1 and 2) [9].

\section{Atrophic Gastritis}

Two main categories are known for chronic gastritis, namely atrophic and non-atrophic one [11]. Atrophy her represents the loss of the appropriate glands due to long exposure to HP infection and usually expressed as major risk factor for gastric cancer. Two types of which are recognized, one represented by fibrosis or proliferation of fibro muscular region in the lamina propria while the other represent intestinal metaplasia [12] due to normal mucosa replacement by the of intestinal type.

\section{H. pylori-associated Atrophic Gastritis}

Helicobacter pylori (HP) is spiral-shaped, flagellated, Gramnegative bacterium which colonizes the stomach of affected individuals $[1,13]$. The bacteria induces dyspepsia, peptic ulcers, acute, chronic gastritis, and mainly responsible for gastric-adenocarcinoma, pancreatic cancer $[14,15]$ additionally several autoimmune diseases.

\section{Routs of Transmission}

Primary transmission rout is through individual exposure to vomit, (fecal-oral) way additionally contaminated water and food participated with family members [16].

\section{Clinical profile}

Infection with HP resulted in symptoms like nausea, vomiting, epigastric pain, hypochlorhydria malaise, fullness and flatulence which may extends to one week regardless any drugs intake or eradication of the bacteria from its location. Chronic gastritis however may appear during persistence of HP infection either asymptomatically or may be manifested as epigastric pain, anorexia additionally nausea and vomiting [17]. Atrophic gastritis may be developed later and characterized by gastric ulcers and adencarcinoma as complications of HP infection. Duodenal ulcer is manifested by burning sensation which may be developed few hours either after meal or at night and disappeared by intake of food.

\section{Relation between HP infection and Oxidative Stress}

Oxidative stress is mainly due to increased Free radical synthesis which is usually manifested in many diseases like chronic gastritis, peptic ulcers, gastric cancer $[18,19]$ and HP infection is mainly responsible for such gastric disorders [20]. Specific HP bacterial strains having certain genotype like cag $\mathrm{A}+\mathrm{Vac}$ As1 may appear more virulent than the others $[20,21]$. Inflammatory response by the gastric epithelium her may lead to the production of interleukin-8 (IL-8) and subsequent generation of ROS additionally other cytokines like TNF- $\alpha$, 
interferon $\Upsilon$ (INF-Y), IL-12 and IL-6 (1). Increased level of NO synthesis was also found in certain diseases like duodenal ulcer, gastritis and gastric cancer [22,23]. This is mostly attributed to certain stimuli like bacterial lip polysaccharides, cytokines that are derived from the bacterial wall [24].

\section{The Inflammatory and Immune Response to HP Infection}

Pathologically gastric inflammation represents the main mediator her since the immune and inflammatory responses have no effect which allow bacterial persistence for long time. Immune response may be only evident with specific virulence factor which increase gastric inflammation, and stimulate the innate immunity. Local immune effectors in addition may be up regulated by an acquired $\mathrm{T}$ helper 1 response [25].

\section{Host response to $H$. Pylori}

The immune response towards bacterial pathogens can be divided into an innate and an adaptive response. The innate response towards bacterial infection is generally initial one as non-specific process, which reacts quickly with several bacterial molecules and directed to kill the bacteria. The adaptive immune response however is delayed and antigen-specific leading to the activation of T, B memory cells and is shaped by the innate immune response.

\section{Innate immunity}

Recognition of bacterial molecules by the innate immune system is mediated by TLRs (Toll-like receptors) expressed on APCs (antigenpresenting cells) such as monocytes and DCs (dendrite cells). Bacterial contact with monocytes and other APCs leads to the secretion of proinflammatory cytokines such as TNF- $\alpha$ (tumor necrosisfactor- $\alpha$ ), IL (interleukin)-1 $\beta$ and IL-8. H. pylori infection has been shown to be associated with increased levels of these cytokines and acting as local chemo attractants [26,27] and inducing granulocytic infiltration [28]. Accordingly many of the studies on innate immune responses to $H$. pylori in epithelial cells have focused onTLR4, the specific 'pathogenrecognition molecule (PRM) of Gram-negative LPS (lipopolysaccharide).

However, gastric epithelial cell lines were non-responsiveto $H$. pylori LPS, even when relatively high concentrations of this endotoxin were added to the cells [29] and Consistent with this, a TLR4neutralizing antibody did not block $H$. pylori-induced secretion of the proinflammatory cytokine IL-8 in AGS cells [30].

\section{Humoral response}

Individuals colonized with $H$. pylori elicit a strong specific systemic and local antibody response to the infection. Tosi and Czinn reported that binding of IgG to $H$. pylori promoted phagocytosis and killing in vitro by polymorph nuclear leucocytes. $H$. pylori strains are susceptible to complement and activate it either via the classical pathway, even in the absence of specific antibodies or by the alternative pathway [31]. Despite this vigorous immune response, $H$. pylori is not eradicated unless an infected individual is treated with a combination of antibiotics, and lifelong chronic infection usually develops. These observations suggest that gastric mucus may be a protective site in which $H$. pylori exist and are relatively inaccessible to specific antibodies or their effector functions.

\section{H. Pylori Vaccine}

Whole formalin-inactivated HP is the only vaccine tested in humans [32] and HP0231 prepared vaccine showed no function [33-35]. Collective vaccine from recombinant cag A, vacuolating cytotoxin A and neutrophil activating protein (NAP) represent a well-known trivalent vaccine [36].

Heat shock proteins (Hsp), highly conserved molecules expressed by both bacteria and mammalian species, possess a range of functions, acting as chaperones for cellular proteins and can activate innate immune receptors. Hsp complex ( $\mathrm{HspC}$ ) vaccines, containing $\mathrm{Hsp}$ derived from pathogenic bacteria, are immune stimulatory without addition of exogenous adjuvant and can induce immunity against their chaperoned proteins [37]. Expression of HP adhesin (HP0410) was reported in food grade bacteria Lactobacillus acidophilus and was used as oral vaccine in experimental mice. This vaccine has proved to be an effective and promising candidate (vaccine antigen) taken in consideration its low cost of preparation [38].

\section{Autoimmune Atrophic Gastritis}

Anti-gastric auto antibodies are detectable in about $30 \%$ of $H$. pylori infected patients. Two major in situ binding sites have been found: first at the luminal membrane in antrum, corpus mucosa and secondly at canalicular membranes. The presence of the latter type of autoantibodies is correlated with the histological and clinical parameters of corpus mucosa atrophy. The gastric $\mathrm{H}+/ \mathrm{K}(+)$-ATPase, which is already known as an auto antigen in classic autoimmune gastritis represents also a major target in atrophic $H$. pylori gastritis [39].

Progressive inflammatory state leading to replacement of parietal cells by atrophic and metaplastic mucosa represents autoimmune gastritis. Autoantibody interaction with parietal cell proton pump and $\mathrm{T}$ cells resulted in breakdown of parietal cells which may resulted firstly to decreased HCL levels and lastly a chlorhydria. Its interaction however with intrinsic factor will affect vitamin $\mathrm{B}_{12}$ absorption leading to megaloplastic anemia which is collectively termed pernicious anemia [40]. Chronic atrophic gastritis patients additionally develop hyper gastrinemia leading to certain carcinoid tumors. Gastrin is expressed by certain studies as cancer risk biomarker and growth factor for certain malignant tumors in stomach, colon, pancreas and liver cancer. Vaccination with antigastrin for individuals having gastrointestinal cancer represents a simple, low cost tool and promising treatment [41].

\section{Tests for $\boldsymbol{H}$. pylori}

Several methods are available to test for $H$. pylori infection.

\section{Breath test (Carbon Isotope-urea Breath Test, or UBT)}

Up to 2 weeks before doing the test intake of antibiotics, bismuth medicines such as Pepto-Bismol and proton pump inhibitors (PPIs) must be stopped.

During the test, a special substance like radioactive urea (harmless) is given [42]. If $H$. pylori are present, the bacteria convert the urea into carbon dioxide, which is detected and recorded in exhaled breath after 10 minutes. This test can identify almost all people who have $H$. pylori and to trace the treatment of the infection. 


\section{Blood tests}

Blood tests are used her to measure antibodies to $H$. pylori and not the current infection where the test can be positive for years even if the infection is cured [43].

\section{Stool test}

A stool test can detect traces of $H$. pylori in the faeces in turn it is a diagnostic tool for the infection and confirm the treatment success [44].

\section{Biopsy}

Biopsy taken through endoscopy from the stomach lining is the most accurate way to confirm $H$. pylori infection and recommended also to diagnose dyspepsia. Testing for $H$. pylori without endoscopy is done only when the indigestion is new, the person is younger than 55 , and there are no other symptoms $[45,46]$. However Convential PCR and multiple Genetic analysis system (MGAS) could be a potential alternative method for clinical detection and to monitor the effectiveness of HP therapy.

\section{Treatments and Drugs}

Depending on the causal factors of gastritis especially acute type due to long intake of non-steroidal anti-inflammatory drugs or alcohol, this can relieved by stopping their use while treatment of the chronic type may require different antibiotics additionally metronidazole.

\section{Gastritis medications}

Generally it is recommended to use a combination of antibiotics with metronidazole for 10-14 days [47]. Proton pump inhibitors like omeprazole are also recommended to decrease gastric acid production and facilitate quick healing [48]. Randomized clinical trial for HP gastritis patients using lansoprazole in combination with clarithromycin, amoxicillin, jinghuaweikang gelatin pearl for 10 days followed by additional 14 days using the gelatin pearl alone showed symptomatic improvement dealing with epigastric pain, bloating and belching [49].

Histamine blockers (H-2) are also recommended like ranitidine and cimetidin additionally antacid although side effects of the latter must be taken in consideration.

\section{Natural products as medication for gastritis}

Tannins and Flavonoids (Phenolic compounds), mostly found in several medicinal plants have usually certain therapeutic effects. Antiinflammatory, antioxidant, anti ulcerogenic and wound healing are mostly attributed to these constituents [50].

Antioxidants content of Fresh vegetables and fruits have beneficial effect on GIT mucosa. Curcumin and black seed oil have significant effect on specific mucosal lesions (ulcers) due to their flavonoids content [51]. Many plants like quassin artichoke, quarcetin have inhibitory influence on cytokine mediated inflammatory mechanism, ulcer healing and suppression of NO synthesis (iNOS). The quassionoidisobrucein $\mathrm{B}$ (isoB), one of the main constituent of Picrolemmasprucei has proved to provide protective effect against NSAID -induced gastritis. This was attributed to reduction in $1 \mathrm{~L}-1 \beta$,
TNFa, prostaglandins additionally leukocyte rolling and migration [52].

Licorice extracts have significant effect on HP gastritis and gastric cancer due to its potent ant oxidative, anti-inflammatory, and antimutagenic actions. The expressions of COX-2, iNOS, VEGF, and IL-8 were increased after $H$. pylori infection, turned to be significantly decreased with s-lico in a dose-dependent manner [53]. Croton campestris A. St.-Hill., popularly known as "vela me do campo", is a species native from savannah area of Northeast Brazil and used by traditional communities in folk medicine for a variety of health problems, especially detoxification, inflammation and gastritis. CCRE a traditional Brazilian medicine against gastric disorders have antinuclear activity, mostly due to its stimulation of NO synthesis and activation of endogenous prostaglandin production [54].

\section{Discussion and Conclusion}

The above article represent a survey on causes, diagnostic tools additionally panel of gastritis treatment. Focus is done on agents inducing acute, chronic types and that in consequence to HP infection. Causes which affect the integrity of gastric mucosa leading to injury and in relation to inflammatory pattern, oxidative stress, hormonal, Enzymes secretion and NO synthesis were also discussed. Role of HP in association with atrophic gastritis, its routes of transmission, symptoms observed in relation to oxidative stress were also reported. Different types of immunity in concern and autoimmune atrophic gastritis were also discussed. Lastly common tests for HP, gastritis medication with special focus on natural products were also outlined.

\section{References}

1. Marshall BJ, Warren JR (1984) Unidentified curved bacilli in the stomach of patients with gastritis and peptic ulceration. Lancet 1: 1311-1315.

2. Dixon MF, Genta RM, Yardley JH, Correa P (1996) Classification and grading of gastritis. Am J Surg Pathol 20: 1161-1181.

3. Szabo S, Trier JS, Frankel PW (1981) Sulfhydryl compounds may mediate gastric cytoprotection. Science 214: 200-202.

4. Hotta K (2000) "Gastric mucus", a mysterious and interesting substance. Trends Glycosci Glycotechnol 12: 59-68.

5. Kasper DL, Braunwald E, Fauci AS, Hauser A, Longo DL, et al. (2006) Harrison. Principios de Medicina Interna.

6. Andersen LP (2007) Colonization and infection by Helicobacter pylori in humans. Helicobacter 12 Suppl 2: 12-15.

7. Voutilainen M, Juhola M, Färkkilä M, Sipponen P (2002) Foveolar hyperplasia at the gastric cardia: prevalence and associations. J Clin Pathol 55: 352-354.

8. Kozlowski W, Jochymski C, Markiewicz T (2011) Gastritis and gastric cancer - New insights in gastroprotection, diagnosis and treatments. Chronic gastritis.

9. Elseweidy MM, Taha MM, Younis NN, Ibrahim KS, Hamouda HA, et al. (2010) Gastritis induced by Helicobacter pylori infection in experimental rats. Dig Dis Sci 55: 2770-2777.

10. Elseweidy MM, Taha MM, Younis NN, Ibrahim KS, Hamouda HA, et al. (2010) Pattern of gastritis as manipulated by current state of Helicobacter pylori infection. BIBIEN 4: 1-9.

11. Rugge M, Fassan M, Pizzi M, Pennelli G, Nitti D, et al. (2011) Operative Link for Gastritis Assessment gastritis staging incorporates intestinal metaplasia subtyping. Hum Pathol 42: 1539-1544.

12. Rugge M, Meggio A, Pennelli G, Piscioli F, Giacomelli L, et al. (2007) Gastritis staging in clinical practice: the OLGA staging system. Gut 56: 631-636.

13. Bruce MG, Maaroos HI (2008) Epidemiology of Helicobacter pylori infection. Helicobacter 13 Suppl 1: 1-6. 
14. Atherton JC (2006) The pathogenesis of Helicobacter pylori-induced gastro-duodenal diseases. Annu Rev Pathol 1: 63-96.

15. Trikudanathan G, Philip A, Dasanu CA, Baker WL (2011) Association between Helicobacter pylori infection and pancreatic cancer. A cumulative meta-analysis. JOP 12: 26-31.

16. Graham DY, Opekun AR, Osato MS, El-Zimaity HM, Lee CK, et al. (2004) Challenge model for Helicobacter pylori infection in human volunteers. Gut 53: 1235-1243.

17. Fischer W, Püls J, Buhrdorf R, Gebert B, Odenbreit S, et al. (2001) Systematic mutagenesis of the Helicobacter pylori cag pathogenicity island: essential genes for CagA translocation in host cells and induction of interleukin-8. Mol Microbiol 42: 1337-1348.

18. Yamaoka Y, Kwon DH, Graham DY (2000) A M(r) 34,000 proinflammatory outer membrane protein (oipA) of Helicobacter pylori. Proc Natl Acad Sci USA 97: 7533-7538.

19. Ding SZ, Goldberg JB, Hatakeyama M (2010) Helicobacter pylori infection, oncogenic pathways and epigenetic mechanisms in gastric carcinogenesis. Future Oncol 6: 851-862.

20. Chen G, Takeuchi Y, Kikuchi R, Arai D, Fukuchi K, et al. (2005) The cause of failure of eradication treatment of Helicobacter pylori. Rinsho Byori 53: 692-697.

21. Moss SF, Legon S, Bishop AE, Polak JM, Calam J (1992) Effect of Helicobacter pylori on gastric somatostatin in duodenal ulcer disease. Lancet 340: 930-932.

22. Mason JM, Delaney B, Moayyedi P, Thomas M, Walt R (2005) North of England Dyspepsia Guideline Development Group, Managing dyspepsia without alarm signs in primary care: new national guidance for England and Wales. Aliment Pharmacol Ther 21: 1135-1143.

23. Delaney B, McColl K (2005) Helicobacter pylori and gastro-oesophageal reflux disease. Aliment Pharmacol Ther 22 Suppl 1: 32-40.

24. Janssen M, Dijkmans BA, Vandenbroucke JP, van Duijn W, Peña AS, et al. (1992) Decreased level of antibodies against Helicobacter pylori in patients with rheumatoid arthritis receiving intramuscular gold. Ann Rheum Dis 51: 1036-1038.

25. Robinson K, Argent RH, Atherton JC (2007) The inflammatory and immune response to Helicobacter pylori infection. See comment in PubMed Commons below Best Pract Res Clin Gastroenterol 21: 237-259.

26. Antos D, Enders G, Rieder G, Stolte M, Bayerdörffer E, et al. (2001) Inducible nitric oxide synthase expression before and after eradication of Helicobacter pylori in different forms of gastritis. FEMS Immunol Med Microbiol 30: 127-131.

27. Kawahara T, Teshima S, Oka A, Sugiyama T, Kishi K, et al. (2001) Type I Helicobacter pylori lipopolysaccharide stimulates toll-like receptor 4 and activates mitogen oxidase 1 in gastric pit cells. Infect Immun 69: 4382-4389.

28. Crabtree J (1996) Immune and inflammatory responses to Helicobacter pylori infection. Scand J Gastroenterol Suppl 31: 3-10.

29. Bäckhed F, Rokbi B, Torstensson E, Zhao Y, Nilsson C, et al. (2003) Gastric mucosal recognition of Helicobacter pylori is independent of Toll-like receptor 4. J Infect Dis 187: 829-836.

30. Su B, Ceponis PJ, Lebel S, Huynh H, Sherman PM (2003) Helicobacter pylori activates Toll-like receptor 4 expression in gastrointestinal epithelial cells. Infect Immun 71: 3496-3502.

31. Berstad AE, Høgåsen K, Bukholm G, Moran AP, Brandtzaeg P (2001) Complement activation directly induced by Helicobacter pylori. Gastroenterology 120: 1108-1116.

32. Kotloff KL, Sztein MB, Wasserman SS, Losonsky GA, DiLorenzo SC, et al. (2001) Safety and immunogenicity of oral inactivated whole-cell Helicobacter pylori vaccine with adjuvant among volunteers with or without subclinical infection. Infect Immun 69: 3581-3590.

33. Aebischer T, Bumann D, Epple HJ, Metzger W, Schneider T, et al. (2008) Correlation of $\mathrm{T}$ cell response and bacterial clearance in human volunteers challenged with Helicobacter pylori revealed by randomised controlled vaccination with Ty21a-based Salmonella vaccines. Gut 57: 1065-1072.
34. Sachs G, Weeks DL, Melchers K, Scott DR (2003) The Gastric Biology of Helicobacter pylori. Annu Rev Physiol 65: 349-369.

35. Michetti P, Kreiss C, Kotloff KL, Porta N, Blanco JL, et al. (1999) Oral immunization with urease and Escherichia coli heat-labile enterotoxin is safe and immunogenic in Helicobacter pylori-infected adults. Gastroenterology 116: 804-812.

36. Malfertheiner P, Schultze V, Rosenkranz B, Kaufmann SH, Ulrichs T, et al. (2008) Safety and immunogenicity of an intramuscular Helicobacter pylori vaccine in noninfected volunteers: a phase I study. Gastroenterology 135: 787-795.

37. Chionh YT, Arulmuruganar A, Venditti E, Ng GZ, Han JX, et al. (2014) Heat shock protein complex vaccination induces protection against Helicobacter pylori without exogenous adjuvant. Vaccine 32: 2350-2358.

38. Hongying F, Xianbo W, Fang Y, Yang B, Beiguo L (2014) Oral immunization with recombinant Lactobacillus acidophilus expressing the adhesin Hp0410 of Helicobacter pylori induces mucosal and systemic immune responses. Clin Vaccine Immunol 21: 126-132.

39. Kirchner T, Faller G (1999) Helicobacter pylori infections and autoimmunity: the interplay in the pathogenesis of gastritis. Verh Dtsch Ges Pathol 83: 56-61.

40. Neumann WL, Coss E, Rugge M, Genta RM (2013) Autoimmune atrophic gastritis--pathogenesis, pathology and management. Nat Rev Gastroenterol Hepatol 10: 529-541.

41. Maddalo G, Spolverato Y, Rugge M, Farinati F (2014) Gastrin: from pathophysiology to cancer prevention and treatment. Eur J Cancer Prev 23: 258-263.

42. Broide E, Shirin H (2015) Evaluation of exalenz bioscience's breathid for helicobacter pylori detection. Expert Rev Mol Diagn 15: 299-312.

43. Feldman M, Friedman LS, Brandt LJ (2010) Sleisenger and Fordtran's gastrointestinal and liver disease: pathophysiology, diagnosis, management, expert consult premium editionenhanced online features: Elsevier Health Sciences.

44. Korkmaz H, Findik D, Ugurluoglu C, Terzi Y (2015) Reliability of stool antigen tests: investigation of the diagnostic value of a new immunochromatographic Helicobacter pylori approach in dyspeptic patients. Asian Pac J Cancer Prev 16: 657-660.

45. Siavoshi F, Saniee P, Khalili-Samani S, Hosseini F, Malakutikhah F, et al. (2015) Evaluation of methods for H. pylori detection in PPI consumption using culture, rapid urease test and smear examination. Ann Transl Med 3: 11 .

46. Uotani T, Graham DY (2015) Diagnosis of Helicobacter pylori using the rapid urease test. Ann Transl Med 3: 9.

47. Scherübl H, Fischbach W, Glocker E, Malfertheiner P (2015) What is new in treating Helicobacter pylori infection? Dtsch Med Wochenschr 140: 277-280.

48. Sakamoto Y, Shimoyama T, Nakagawa S, Mikami T, Fukuda S (2014) Proton pump inhibitor treatment decreases the incidence of upper gastrointestinal disorders in elderly Japanese patients treated with NSAIDs. Intern Med 53: 1107-1111.

49. Wang TT, Zhang YM, Zhang XZ, Cheng H, Hu FL, et al. (2013) Jinghuaweikang gelatin pearls plus proton pump inhibitor-based triple regimen in the treatment of chronic atrophic gastritis with Helicobacter pylori infection: a multicenter, randomized, controlled clinical study. Zhonghua Yi Xue Za Zhi 93: 3491-3495.

50. Elseweidy MM (2011) "Gastritis and Gastric Cancer - New Insights in Gastroprotection, Diagnosis and Treatments", Role of Natural Antioxidants in Gastritis. INTECH Open Access Publisher.

51. Elseweidy MM, Younis NN, Amin RS, Abdallah FR, Fathy AM, et al. (2008) Effect of some natural products either alone or in combination on gastritis induced in experimental rats. Dig Dis Sci 53: 1774-1784.

52. Vieira SM, Silva RL, Lemos HP, Amorim RC, Silva EC, et al. (2014) Gastro-protective effects of isobrucein B, a quassinoid isolated from Picrolemma sprucei. Fitoterapia 95: 8-15.

53. Park JM, Park SH, Hong KS, Han YM, Jang SH, et al. (2014) Special licorice extracts containing lowered glycyrrhizin and enhanced 
Citation: Elseweidy MM (2017) Brief Review on the Causes, Diagnosis and Therapeutic Treatment of Gastritis Disease. Altern Integr Med 6: 231. doi:10.4172/2327-5162.1000231

Page 6 of 6

licochalcone A prevented Helicobacter pylori-initiated, salt dietpromoted gastric tumorigenesis. Helicobacter 19: 221-236.

54. Júnior FE, de Oliveira DR, Boligon AA, Athayde ML, Kamdem JP, et al.

(2014) Protective effects of Croton campestris A. St-Hill in different ulcer models in rodents: evidence for the involvement of nitric oxide and prostaglandins. J Ethnopharmacol 153: 469-477. 